\title{
Roma Parents' Perceptions on Education
}

\author{
Dimitris T. Zachos ${ }^{1 *}$, Antigoni Panagiotidou ${ }^{2}$ \\ ${ }^{1}$ School of Primary Education, Aristotle's University of Thessaloniki, Greece \\ ${ }^{2}$ University of York, United Kingdom \\ Email: dimzachos@eled.auth.gr
}

\begin{abstract}
Politicians and academics from various European countries dealing with the issues of the Roma strongly believe that education can help Roma individuals and groups social integration and improve their living conditions. Therefore, a series of policies measures and programs have been set up to target the educational integration of pupils of Roma origins. What is missing from these actions are the views of Roma themselves. This exactly is the aim of our paper: to give a voice to those parents of Roma origins, whose children go to school or ought to go to school. Our study is based on a qualitative research where participants are individuals of Roma origins living in the suburbs of Thessaloniki (Greece). According to our finding, it seems that Roma parents' that contributed to our research approaches and attitudes broke down some basic and well-established myths about education.
\end{abstract}

Keywords: Roma, parents, education, Greece.

\section{Introduction}

In most cases, during the period nations - states were born, their national and ethnic minorities were forced to abandon their distinct cultural elements. Education was the basic state apparatus whereby nationalist ideology was transmitted to students. National homogenization was one of the main reasons most nation - states established formal education and made schooling compulsory.

An effort made by the League of Nations during the Interwar period to raise the issue of minorities' rights was abandoned due to the spread of fascist governments in Europe (Mazower, 1997). After World War's II, all nations declared their willingness to protect human rights and dignity, and fight against racism and discrimination (United Nations, 1948). Nevertheless, assimilation policies characterized the treatment of ethnic / ethnic / culturally diverse groups till the 1990s. As a result, in most countries education continued to have a nationalistic character until the end of the 1990s: National identities were promoted by strictly controlled nationalistic curricula, and schools' and teachers' everyday practices (hoisting the flag, singing the national anthem, displaying national symbols in the halls, ceremonies on national holidays etc.) (Zachos and Michailidou, 2014). Students from ethnic and cultural minority groups were not represented at all in school curricula and textbooks (Zachos, 2017b).

Over the past thirty years, in Europe and other regions of the continent, this situation has begun to change. Several states have attempted to facilitate the educational integration of their ethnically / culturally different populations. Curricula have been redesigned, textbooks have been rewritten and school teachers have been trained in the context of intercultural communication and education.

Whether and to what extent these efforts have so far been successful, is a topical and controversial issue. What we think is missing from these actions are the views of Roma themselves. This exactly is the aim of our paper: to give a voice to those parents of children who go to school or who ought to go to school. How do they value education, how do they judge school system?

\section{Roma and Education: Some Critical Remarks}

Roma are called individuals and groups living in Europe and America, well-known as Gypsies, Tsingani, Bohémiens, Gitani and Gitanos. Roma are anything but a homogeneous group, but they have certain cultural similarities (traditions, customs) and historical experiences (suffering prejudice, discrimination 
and racist attitudes, displacements, movements and persecutions, low pay and work status) (Zachos, 2006, 2007, 2011, 2012, 2014, 2017a). Although Roma groups do not have a strong collective political representation, over the last thirty years they have attracted the interest of international organizations and associations such as the United Nations and the European Union. In our opinion, it happened because of Roma economic and social status. Roma groups ranks among the poorest people in Europe (Themelis, 2009).

Their condition has been acknowledged by the European Union, which has set as a goal the protection of the Roma and has begun a series of initiatives aiming at reversing the cycle of poverty and inequality of Roma groups (European Commission, 2012). Though it seems that these initiatives have not brought major improvements to the lives of most Roma (Ram, 2010), they have helped introduce positive measures and activities for Roma themselves, as well as other culturally and ethnically different residents of countries within the European Union.

More specifically, European Union institutions have highlighted students of Roma origins education as an issue of high importance for their social integration, since their exclusion from education and the consequent lack of qualifications (diplomas, certificates) perpetuates their poverty and marginalization. Thus, for almost thirty years, financial resources have been allocated to design and carry out a series of programs of Compensatory Education.

Those programs have produced numerous papers at a multitude of conferences and meetings. This is the reason why Roma education is an issue concerning more than the usual players (Ministry of Education, Universities, Research Institutes, independent researchers). Non-Governmental Organizations, Local Authorities, and even churches have organized and carried out educational interventions. As a result, there are many researches on Roma education, a number of which does not meet strict academic criteria. In other words, some of the data concerning Roma students' schooling that is available to us (usually via internet) come from reports that present the results of a number of funded projects, whose methodology and reliability -in our opinion- are questionable.

Another issue which arises in a sizable portion of the papers of this type is that they unwittingly contribute to the preservation and even strengthening of established stereotypes surrounding Roma identity and their (supposed) a distinct and one-of-a-kind Romani culture. So, they compare Roma groups that are varied and heterogeneous amongst themselves and their cultural characteristics to see to what extent they correspond to this (supposed common) Roma culture.

This downplaying of the internal social differentiations that exist among Roma groups and helps to preserve some misconceptions concerning Roma groups under which Roma are a nomadic people; a cohesive, homogenous group; they are thought to get involved in politics only to serve their own petty interests and therefore always vote for the leading parties; in this view as well, education is not seen as compatible with Romani culture and schools are thought of as institutions alien to the Roma (Zachos, 2018).

This focus on issues of identity and culture actually works against the aim of uncovering the true causes of educational failure by students of Roma origins which in our opinion are poverty, social exclusion and marginalization. As we have repeatedly emphasized (Zachos, 2007, 2014, 2017a, 2017b), the financial problems most Roma face, as well as their group's low social status are the main obstacles to students of Roma origin's efforts to integrate in schools and achieve success at the same rate as the Gadje (non-Roma).

At this point we should emphasize that even those students of Roma origins who have escaped from poverty can have problems with discrimination at school, if their family has not abandoned their distinguishing cultural elements. In other words, students of Roma origins are most likely to face problems due to their origin. There are still many negative stereotypes, and many prejudices about Roma (Riley, 2008, 12), which provide fertile ground for racism (Traynor, 2009). One of the most resonant cases where students of Roma origins are victims of institutional racism is that of their segregation into «special schools for the mentally and physically handicapped» (Ringold, Orenstein and Wilkens, 2003). A policy that has been condemned by the European Court of Human Rights (O'Nions, 2010).

Another problem many students of Roma origins face has to do with their mother tongue (Romani). Upon entering the formal educational system in European countries, many students of Roma origins are at low level of competence in the language of instruction (Filipović, Vučo and Djurić, 2010). 
Hence, we advocate the position that «educational systems have not helped the Roma» (Claveria and Gomez - Alonso, 2003) to integrate. State controlled curricula ignore Roma history, accomplishments, everyday activities and culture (Zachos, 2017b). Schools are not well prepared to work with students of Roma origins, while (some) teachers do not have sufficient knowledge and understanding of Roma group distinctiveness and sometimes they forced to improvise to help Roma origins students (Zachos, 2017a).

\section{Parents' of Roma Origins Relation with School}

Despite the increased interest in Roma education, their views are still rarely heard or displayed. There has been comparatively little research looking at the experiences of individuals of Roma origins in formal education settings (Bhopal and Myers, 2009). In other words, the views, emotions, and attitudes both of students of Roma origins, and of their parents have not been studied or taken into consideration in the drafting of education policies, as well as in the training programs concerning them.

The question of the views of parents of Roma origins on issues related to their offspring's schooling are of particular interest, since parents constitute the third factor in the educational process (students teachers - parents). As a number of studies pertaining to this issue show, parents' firm support of their children constitutes one of the most vital factors of a successful educational career (Rose, Gallup and Elam, 1997). Parents ' involvement in their children's school life can help them achieve more and may increase the student's chances at academic success (Brough and Irvin, 2001, Epstein, 1995, 2001). It must be noted that parents' participation in children's education, rather than other 'commissioned' individuals, is more effective when it begins in the pre-infant age (Cotton and Wikelund, 1989).

On the other hand, lack of parental involvement constitutes the greatest problem that schools face (Rose, Gallup and Elam, 1997). That is why educational authorities, administrators and teachers need to find ways to engage parents -especially those of children from vulnerable groups- with their schools. The importance of parents' involvement in their children's education and their support has been emphasized in discussions concerning the achievement gap between economically disadvantaged and middle-class children (Drummond and Stipek, 2004). The schooling of students of Roma origins can be decisively influenced by the quality of the home-school relationship. The views of parents of Roma origins concerning the ways in which schools can contribute to their children's well-being is a factor of great importance for their relationship with the school (Wilkin et. al., 2009). According to relevant researches, which are listed below, parents of Roma origins believe that their relationship to formal education is affected by a number of factors. The first, originates from a fear of losing their culture. In other words, some individuals of Roma origins consider formal education as a threating their cultural particularities. Characteristically, in a research by Levinson and Sparkes (2006), parents of Roma origins expressed fears that in schools, there is a process whereby their children are at risk of losing part of their cultural identity. In the same vein, in a survey distributed by Lloyd and McCluskey (2008), most parents of Roma origins expressed fear that if their children attend school normally, then they will move away from the values and ethics of their community, weakening their culture.

A second issue raised by parents of Roma origins comes from their negative experiences in schools. According to Lloyd and McCluskey (2008, 339), negative experiences are the cause of reservations that some individuals of Roma origins have regarding the treatment that their children may receive in schools. Verbal and physical attacks, as well as bullying are a major concern. Myers, McGhee and Bhopal (2010) report that parents of students of Roma origins feel that the prejudice and racism their children face in schools, are factors that push them to become either victims of bullying or bullies. Lloyd and McCluskey (2008) stated that there are many incidents of bullying and racist behavior against students of Roma origins, not only from their peers, but even from some teachers. In order to protect themselves, some parents often ask their children to only form friendships with other students of Roma origins (Derrington, 2007).

A third issue characterizing the relationship of parents of Roma origins with schooling concerns their inability to offer their children the right conditions and necessary means. Low family income does not allow them to provide tools and manuals, as well as suitable space (like separate room with the appropriate heating and lighting) so that their children can comfortably focus on reading (Pahic, Vidovic and Ridicki, 2011). Furthermore, many parents of Roma origins may not have attended or 
finished formal schooling themselves (Parthenis, 2016), and so they are unable to help their children fulfill their learning obligations.

A fourth issue relates to the extent that children belonging to Roma groups know and use the official language of the school. Some parents of Roma origins believe that it is more difficult for their children than for children of Gadje- to read at home, mainly because of the language barrier (Pahic, Vidovic and Ridicki, 2011).

A fifth issue concerns the content of the curriculum. parents of Roma origins feel that a curriculum based on practical issues would be more appropriate to their children (Bhopal, 2004, 36).

Finally, a sixth issue, which is directly related to the previous released issues, concerns the lack of high expectations that parents of Roma origins have for their children's schooling. When parents of Roma origins -as any other parent- have high aspirations for their children, then their children are more likely to adopt them as well (Padfield, 2005) and be more successful in school. When parents express their desire to see their children complete school so they can have a better job (Penderi, Petrogiannis, Tsioumis, 2009), then it is more likely that their children will try harder to achieve this goal.

Another issue is whether parents of Roma origins have an interest in their children's academic progress and they work together enough with their children's' schools. The studies of Dominguez (1999) and Zake (2011) gave a negative answer, arguing that the Roma are not interested in the education of their children. However, other studies show that the number of parents who value education and want their children to have regular attendance is increasing (Levinson, 2008). Some families of Roma origins do believe that school education is an advantage to their children's efforts to integrate and succeed in a rapidly changing world (Kiddle, 2000). That is why these parents are heavily involved in their children's every day school activities (reading, math, helping with homework, and knowing what their child is learning) (Drummond and Stipek, 2004). Than these studies show, education is not "outside of Roma culture" and it is included in the values of (at least several) individuals and families of Roma origins. These people believe that schools do help their children, but that also schools could do more (Pahic, Vidovic and Ridicki, 2011). That is why educational policy, educational organizations, schools and teachers should strive to earn the trust of parents of students of Roma origins. When they have positive attitude towards education, when they value education, then it is more possible their children stay in school longer (Derrington and Kendall, 2007).

To summarize, parents of Roma origins believe that schools can offer different learning environments and a rich variety of subjects in curricula, to help children of Roma groups members feel comfortable (Myers, McGhee and Bhopal, 2010). Parents of Roma origins asks for extra lessons (especially language lessons given their linguistic problems), free meals and snacks and cheaper (or old) books (Pahic, Vidovic and Ridicki, 2011). Schools could also provide extra-curricular activities such as after-school clubs, festive events with attractive themes that would bring together teachers and parents, as well as guardians and Roma communities.

\section{Methodology}

The primary objective of our research was to contribute to the knowledge and understanding of the factors that determine how well students of Roma origins integrate in formal academic environments and what leads to their improved academic performance. Our central aim was to explore the views, perceptions and attitudes of individuals and families of Roma origins vis-à-vis their children's schooling. Our main research questions were: First, what are the parents of Roma origins expectations from their children's schooling? Second, what kind of relationship do parents of Roma origins want to build between them and their children's school? Third, how do parents of Roma origins contribute to the schooling of their youth?

Our research strategy was Case Study, one of Creswell's (1998) five qualitative strategies. Our main research technique was the semi-structured, in-depth interview. The interview was the most appropriate method to collect data since we wanted to understand in depth participants' experiences expressed in their own words (Robson, 2007). The semi-structured in-depth interview is based on a core set of questions which examined issues corresponding to our research questions. However, in contrast to the structured interview where he/she who is being interviewed is called upon to answer within a 
predetermined research framework, the semi structured in-depth interview allows "subjects" the possibility of elaborating on other issues, giving their own interpretations, commenting, etc.

In accordance with our scientific approach and practice, we attempted to place participants' views within their current historical, political, economic and cultural context. In order to achieve this goal, we conducted a literature review of primary and secondary sources in Greek and English languages.

\subsection{Participants}

Twenty individuals, members of Roma groups living in a specific area of Thessaloniki's suburbs were the participants of our research (more analytically see table, 1 and 2).

Table 1. Participants' age and sex.

\begin{tabular}{ccc}
\hline Age & Man & Women \\
\hline $20-30$ & 8 & 10 \\
$30-40$ & 2 & 0 \\
$40-50$ & 0 & 0 \\
$50-60$ & 0 & 0 \\
\hline
\end{tabular}

Table 2. Participants' educational degrees.

\begin{tabular}{c|ccc|cc}
\hline \multirow{2}{*}{ Sex } & \multicolumn{3}{|c|}{ Primary Education } & \multicolumn{2}{c}{ Secondary Education } \\
\cline { 2 - 6 } & Didn't go & Didn't finish & Finished & Didn't finish & Finished \\
\hline Man & 0 & 1 & 7 & 2 & 0 \\
Woman & 3 & 0 & 3 & 3 & 1 \\
Total & 3 & 1 & 10 & 5 & 1 \\
\hline
\end{tabular}

Participants in our research live in a suburb of Thessaloniki, in large blocks of flats given to them fifty years ago. There are two primary schools near their homes, where their children study. We approached most of them through certain key people in the area (mostly teachers, social workers, priests). In some cases, we spoke with and interviewed men and women whom we met on the streets while we were walking through their neighborhood (mahala), some of them were sitting in their yards, others were waiting to pick up their children from school while others resting at local cafes or playgrounds.

\subsection{Data Collection and Analysis}

Data was collected through in-depth interviews with twenty parents of Roma origins in Thessaloniki (Greece) and observation of their children's participation in two local schools. The duration of these interviews was forty-five minutes to two hours. Sixteen of the twenty interviews were recorded while we kept detailed notes for the remaining four. We also had -out of schedule- unrecorded conversations of varying lengths with twenty parents of Gadje (non - Roma) students living in the specific area and fourteen teachers and administrators from the two schools, which we recorded in detailed field notes and journals.

We informed participants about the purpose of our research, and gave them a "research contract", explaining that we were committed to preserving their anonymity and informing them of the results of our research.

We analyzed the data through thematic analysis, an on-going process of transcription, coding, and writing. Our data (recorded interviews, field notes and journal) was transcribed by hand and coded using the five - stage coding model (Braun and Clarke, 2006). Five themes emerged from the data which we present below citing relevant excerpts from the data to strengthen their validity (cf. Braun and Clark 2006). 


\section{Themes}

\subsection{Education as a Value}

As we already mentioned, studies show that there has been marked increase in positive attitudes among individuals of Roma origins regarding the value of education. All the participants in our study considered education to be valuable to their children and that going to school provided their children with significant benefits:

"School can offer a lot! First of all, hmmm... a human being becomes ... how can I say it... attending school makes you brighter... with a culture more..." (N.L. woman, 27).

"Sharp brain, behave well... learning to respect each other, to learn their lessons well.". (N.T. woman, 25).

Some of the participants had some reservations about the usefulness of education. However, it seems that they also evaluated education positively, and as something good for their children's lives,

"Yes, all right it is something relevant to this era, it can be tough but hmm... you don't know what is really happening but school must exist; they have to go" (K.K. man, 32).

"They have to practice an art to create their own path; teach them and then let children create their own path... and later companies shall come and find from among the students who is better for the job "bring this one to me'... this can happen" (S.D woman, 23).

We should also mention that of the concerns of some participants were far from being trivial questions or thoughts:

"Life changes radically for some families, when children achieve more than their parents. Underground life style also becomes more rare. Children must escape, change their life style. We, the ROMA, need this" (M.N. woman, 27).

"We would like there to be a lesson in school to stop racism, a lesson for Roma children, [to help theml integrate into wider society; not being closed-minded like 'a gypsy will eat you,' this is what happens in school 'there are Gypsies, watch out!'... children are isolated. They feel isolated by society. This is a bad thing!" (M.M. woman, 22)

"Integrate our children, because if you don't, they will become thieves or drug dealers. It's the easier choice, because we are dark skinned and if we ask for a job they won't offer us one, because they will call us gypsies - thieves" (S.N man, 36).

\subsection{Time Dedicated to Their Children's Education}

Parents of our research spend time with their children and they try to help them with their schoolrelated obligations. As most of them said, they would like to contribute more substantially to their children's' schooling:

"I look for merchandise, then come back home and have to cook.... I also see how my children spent their day, if everything is all right. I like their company, to talk a little bit, to share some thoughts. Get closer to each other... so I dedicate much more time to my children, to my family» (L.F. woman, 29).

There is particular interest in cases where some participants in our research declared that because of their inability to help their children do their homework, they pay others to do it:

"I pay some literate girls from what little money I have. We are talking about 5 Euros per hour, do not think more, to help my children, to prepare them for school" (K. M., man 24).

Some participants in our research also spend money and time on extracurricular activities, like sports, dance lessons etc.).

"My sons go to football club... I pay fifty Euros per month. So, I cannot pay for private tutors. I wish could...I don't want them to have the difficulties I faced in life" (N. P., man 32).

"I run to Tutorials [after school paid classes in a kind of private school], then I take them back, I run to football club, gym... full time with my children « (M.M. man 25). 


\subsection{Personal Experiences from Schooling}

Parents who participated in our research own experiences from school are very likely to exert influence in determining their children's educational failure or success. Our participants showed nostalgia when they made comparisons between their school years and those of their children:

"It was a nice time, many young boys and girls together, much better -as I hear-from nowadays where my sons go to school. We completed our schoolwork all together, but we did not have all-day school [a school is called "oloimero" if it operates until 16.00]" (A.A. woman, 24).

Whereas negative experiences left deep wounds:

«My classmates and I were beaten by my teachers and some even expelled. As I child, I was a little naughty. In those days, teachers didn't call your parents etc. you had just to open your arms and they beat you with a stick or you earned a heavy smack to your face" (L.K., man, 31).

Very good teachers had memorable positive effects too:

"My teacher taught me to go to the theatre, to love cinema and the arts. These days we have no idea about those activities. If only I had some money to go again and take my children with me» (E.S., woman, 37).

\subsection{Relationships with Their Children's School}

The quality of the relationship between parents with formal education is an important factor in determining if a child is likely to be successful in school. Our participants, as seen in their interviews, strongly believe that they should be active members of their school communities:

"I go to my child's school every day. I pick him up and have some sort of conversation with his teacher. I need to know how he spends his time away from home" (M.S. woman, 27).

"Although I went to only a few classes in primary school, I do care about my children's homework" (N.D. man, 28).

Of course, there are dissenting voices:

«To tell the truth, I go to the school only after a call from the principal» (K.M. man, 27).

"My children love their teachers! They love school and I go with them. But there is usually one day per week when they cannot go to school" (N.M. woman, 26).

As far as the quality of the relationship of parents that participated in our research with school administrators and teachers is concerned, our participants seemed to be satisfactory. However, some of them raised the issue of racist incidents and expressed their desire for improved legislation and, more generally, better treatment by the state,

«We are pleased to be at this school. If my child were attending another school, he probably would have been expelled" (K.F. man, 27).

"Our race is now modernizing and growing; [we are] educating our children. Take note that many Roma parents are still illiterate. Our improved relationship with schooling began only twenty years only ago» (N.K. woman, 25).

"Sometimes we have racist teachers. Others are old enough to care for us. The state needs to protect and help us" (D.M. woman, 23).

It is noteworthy that participants in our research believe that students of Roma origins receive better treatment in primary schools than in secondary schools:

"In high school, we have no knowledge about why teachers do what they do. You can't even ask them" (K.S. woman, 29)

"In high school, teachers only call us when they want to inform us about our children's misbehavior.... we feel like we don thave easy access there" (A.B. man, 31).

\subsection{Aspirations for Their Children's Educational Success}

Some parents that participated in our research expect a "happy ending" to their children's path through school:

"I want my child to become a doctor or lawyer - the same thing every mother wants" (L.M. woman, 28). 
"I have two sons. The first one wants to become a district attorney. The second one wants to become a priest" (K.K. man, 27).

"My daughter's wedding will not bring me joy. I want her to study. I do not agree with quick marriages" (N.N., woman, 25).

Other participants expressed a more "pessimistic" view about the educational prospects and limits of their children:

"They should open a store. They cannot achieve anything else. Working in an office seems like an impossibility" (G.T. man, 29)

"The health of my children concerns me. Nothing else. They will find their way" (F.T., man, 38).

But almost all of the men and women that participated in our research agree that schooling can provide their children with resources, which will be useful in any job they do,

"Whatever my son is going to do for a living,; the knowledge that he gains from school will be valuable" (K.S. woman, 29).

"I tell my children every day: at school you will learn to talk, behave properly and work systematically" (C.G. $\operatorname{man}, 37)$.

\section{In Lieu of an Epilogue}

Parents' of Roma origins that participated in our research views have been formed under the influence of some objective factors. The most important of those factors, according to our opinion, is the fact that almost all Roma groups have lived in isolation and on the margins of society for so long, led many of them to develop defense-mechanisms against enforced state educational policy and the way it was implemented in schools (Katsikas and Politou, 1999). So many years of social exclusion made a portion of individuals of Roma origins feel threatened by school (Lloyd, Stead, Jordan and Norris, 2003).

Formal education does not seem to be included in the priorities of many individuals and families of Roma origins. This does not mean however that they reject schooling. The poverty that they experience, as well as certain aspects of their culture (such as speaking a different language from that of the language of instruction) that schools do not take into account, are factors that hamper Roma students' educational integration. The way school is organized makes it unfriendly and unattractive to them. Bureaucracy and arrogance in formal education brought students of Roma origins failure (Riley, 2008, $15)$.

The people who participated in our research broke down some basic and well-established myths about Roma, chief among them concerning their attitudes towards education. First, they include education in their system of values, destroying the myth that wants Roma Romani culture to be incompatible with the culture of school. Parents of Roma origins that participated in our research believe that education can have a very positive influence not only to their offspring's professional lives, but to their character and social life too. And this happens despite the fact that they do not always have positive experiences from their school years.

Second, set aside as much time as they can to actively participate in the curricular and extracurricular activities of their children, and they attempt in every possible way to help them get ahead. These attitudes are not compatible with the widespread approach, according to which Roma parents are not interested in educating their children.

We believe that a closer relationship between parents of Roma origins and schools is necessary. To achieve this goal, we should: First, categorically reject stereotypes and folk assumptions, according to which Roma have a 'natural' disaffection with school (Flecha and Soler, 2013). Second, refuse the widespread view, according to which Roma families are barriers to their children's education, as well as the idea that parents of Roma origins are not involved in their children's schooling because of lack of interest or willingness to participate (Claveria and Gomez Alonso, 2003). Third, to recognize that the prejudice against any group of Roma and its' culture (as a whole), is different from condemnation of certain practices or habits. When these conditions are fulfilled, then it will be possible to eliminate the scornful descriptions and references to Roma students, as well as those attitudes and actions that alienate and make parents of Roma origins hostile to schools. Thinking that the Roma community should be «repaired» (Riley, 2008) does not help, especially when it is established as a precondition for further cooperation. 
We strongly believe that educators, administrators, journalists and politicians who deal with the education of Roma origins students, should be convinced that school can play a crucial role in the social integration of those individuals and groups with different cultural backgrounds. Education can be a powerful weapon in the battle to reverse the cycle of inequality that characterize the lives of many European Roma groups (Flecha and Soler, 2013); it can contribute to their upward mobility, better their living standards (Zachos, 2007) and lead more generally to a better society.

\section{References}

1. Bhopal, K. (2004). Gypsy Travellers and Education: Changing Needs and Changing Perceptions. British Journal of Educational Studies, 52(1), 47-64.

2. Bhopal, K., \& Myers, M. (2009). Gypsy, Roma and Traveller Pupils in Schools in the UK: Inclusion and 'Good Practice'. International Journal of Inclusive Education, 13(3), 299-314, DOI: 10.1080/13603110701748403

3. Braun, V., \& Clarke, V. (2006). Using thematic analysis in psychology. Qualitative Research in Psychology, 3(2), $77-101$.

4. Brough, J., \& Irvin, J. (2001). Parental Involvement Supports Academic Improvement Among Middle Schoolers. Middle School Journal, 32(5), 56-61.

5. Creswell, J. W. (2011). John W. Creswell: I Ereyna stin Ek/si [Research in Education] Athens: Ion.

6. Creswell, J. (1998). Qualitative Inquiry and Research Design. Choosing Among Five Tradition. Thousand Oaks, CA: Sage.

7. Drummond, K. V., \& Stipek, D. (2004). Low-Income Parents ' Beliefs About Their Role in Children's Academic Learning. The Elementary School Journal, 104(3), 197-213.

8. Clavería, J. V., \& Gómez Alonso, J. (2003). Why Romà Do Not Like Mainstream Schools: Voices of a People without Territory. Harvard Educational Review, 73(4), 559-590.

9. Cotton, K., \& Wikelund, K. (1989). "Parent Involvement in Education". Retrieved May 11, 2017 from http://multiculturaleducole.pbworks.com/w/file/fetch/55317746/ParentInvolvementinEducation.pdf

10. Derrington, C. (2007). Fight, Flight and Playing White: An Examination of Coping Strategies Adopted by Gypsy Traveller Adolescents In English Secondary Schools. International Journal of Educational Research, 46(6), 357-367.

11. Derrington, C., \& Kendall, S. (2007). Still in school at 16? Conclusions from a Longitudinal Study of Gypsy Traveller Students in English Secondary Schools. In G. Bhatti, C. Gaine, F. Gobbo, and Y. Leeman, (Edit.) Social Justice and Intercultural Education: An Open-Ended Dialogue. Stoke-on-Trent: Trentham Books.

12. Dominguez, S. P. (1999) Teachers' Attitudes About the Integration of Roma: The case of Spain. European Journal of Intercultural Studies, 10(2), 219-231.

13. European Commission (2012). "Roma and Education: Challenges and Opportunities in the European Union". Retrieved May 2, 2017 from http://bookshop.europa.eu/en/roma-and-education-pbNC3111389/

14. Epstein, J. L. (1995). School/family/community Partnerships: Caring for the Children We Share. Phi Delta Kappan, 76(9), 701-712.

15. Epstein, J. L. (2001) School, Family, And Community Partnerships: Preparing Educators and Improving Schools. Boulder Co: Westview Press.

16. Flecha R. and Soler, M. (2013). Turning Difficulties into Possibilities: Engaging Roma Families and Students in School Through Dialogic Learning. Cambridge Journal of Education, 43(4), 451-465, DOI: 10.1080/0305764X.2013.819068453

17. Filipović, J., Vučo, J., \& L. Djurić, (2010). From Language Barriers to Social Capital: Serbian as the Language of Education for Romani Children. In Prior, M. T., Y. Watanabe, and S.-K. Lee (edit.) Selected Proceedings of the 2008 Second Language Research Forum (261-275). Somerville, MA: Cascadilla Proceedings Project.

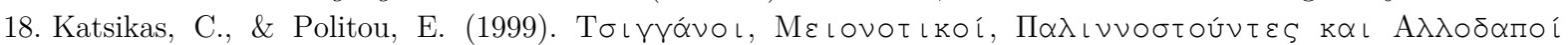

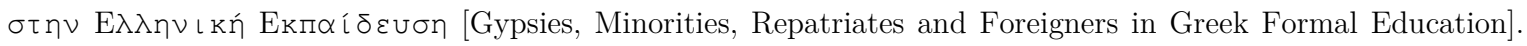
Athens: Gutenberg.

19. Kiddle, C. (2000). Partnerships Depend on Power-Sharing: An Exploration of The Relationships Between Fairground and Gypsy Traveller Parents and their Children's Teachers in England. International Journal of Educational Research, 33(3), $265-274$.

20. Levinson M. P. (2008). Issues of empowerment and disempowerment: Gypsy children at home and school. International Journal of Citizenship Teaching and Learning, 4(2), 70-78. 
21. Levinson, M.P., \& Sparkes, A.C. (2006). Conflicting Value Systems: Gypsy Females and the Home-School Interface. Research Papers in Education, 21(1), 79-97.

22. Lloyd, G., \& McCluskey, G. (2008). Education and Gypsies/Travellers: "Contradictions and significant silences" International Journal of Inclusive Education, 12(4), 331-145.

23. Lloyd, G., J. Stead, E. Jordan, \& C. Norris (2003) Teachers and Gypsy Travellers. In M. Nind, K. Sheehy \& K. Simmons (eds), Inclusive Education: Learners and Learning Contexts. London: Fulton.

24. Mazower, M. (1997). Minorities and the League of Nations in Interwar Europe. Daedalus, 126(2), pp. 47-63.

25. Myers, M. McGhee, D., \& Bhopal, K. (2010). At the Crossroads: Gypsy and Traveller Parents' Perceptions of Education, Protection and Social Change. Race Ethnicity and Education, 13(4), 533-548, DOI: $10.1080 / 13613324.2010 .492138$

26. O'Nions, H. (2010). Different and Unequal: The Educational Segregation of Roma Pupils in Europe. Intercultural Education, 21(1), 1-13, DOI: 10.1080/14675980903491833.

27. Padfield, P. (2005). Inclusive Educational Approaches for Gypsy / Traveller Pupils and Their Families: An Urgent Need for Progress. Scottish Educational Review, 37(2), 127- 144.

28. Pahic, T. Vidovic, V. V., \& Miljevic-Ridicki, R. (2011). Involvement of Roma Parents in Children's Education in Croatia: A Comparative Study. Journal of Research in International Education, 10(3), 275-292.

29. Parthenis, C., \& Fragoulis. G. (2016). "Otherness" as Threat: Social and Educational Exclusion of Roma People in Greece International Journal of Multicultural Education, 18(2), 39-57, DOI: http://dx.doi.org/10.18251/ ijme.v18i2.1132

30. Robson, C. (2007). H '

31. Rose, L.C., Gallup, A.M., \& Elam S.M. (1997). The 29th Annual Phi Delta Kappan/Gallup Poll of the Public's Attitude Toward The Public Schools. Phi Delta Kappan, 79(1), 41-56.

32. Penderi, E., Petrogiannis, K., \& Tsioumis, K. (2009). The hypothesis of "cultural discontinuity" in the Greek primary education: An example of teachers and Roma mothers' ideas and expectations about 1st grade students' competencies. In: Proceedings (CD-ROM) of the International Conference Intercultural Education: Paideia, Polity, Demoi, Athens, June 22-26.

33. Ram, M. H. (2010). Interests, Norms and Advocacy: Explaining the Emergence of the Roma onto the EU's Agenda. Ethnopolitics, 9(2), 197-217, DOI: 10.1080/17449050903117222

34. Riley, K. L. (1997). Education in the United States and the Rom. The Educational Forum, 61(1), 12-17.

35. Ringold D., Orenstein, A. M., \& E. Wilkens, (2003). "Roma in an Expanding Europe: Breaking the Poverty Cycle". Retrieved June 17, 2017 from http://documents.worldbank.org/curated/en/339671468774851207/ pdf/301760PAPER0Ro1ope01see0also0305161.pdf

36. Themelis, S. (2009). Questioning Inclusion: The Education of Roma/Traveller Students and Young People in Europe and England - A Critical Examination. Research in Comparative and International Education, 4(3), 262-275.

37. Traynor, I. (2009, April 23). "Gypsies suffer widespread racism in European Union". The Guardian. Retrieved June 11, 2017 from https://www.theguardian.com/world/2009/apr/23/eu-roma-racism-discrimination

38. United Nations (1948). Universal Declaration of Human Rights.

39. Wilkin, A., Derrington, C., White, R., Martin, K., Foster, B. Kinder, K., \& Rutt, S. (2010). Improving the Outcomes for Gypsy, Roma and Traveller Pupils: Final Report. Retrieved from http://www.education.gov.uk/schools/pupilsupport/inclusionandlearnersupport/mea/Improvingachievement/a0 012528/gypsy-roma-and-traveller-achievement

40. Zachos, D. (2006). Roma, Egalitarianism and School Integration: The Case of Flampouro. Journal for Critical Education Policy Studies, 4(2). Retrieved June 11, 2017 from http://www.jceps.com/index.php?pageID= article\&articleID=76\#top

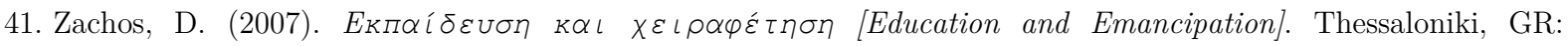
Epikentro.

42. Zachos, D. (2011). Sedentary Roma (Gypsies): The Case of Serres (Greece). Romani Studies, 21(1), 23-56.

43. Zachos, D. (2012). Institutional Racism? Roma Children, Local Community and School Practices. Journal for Critical Education Policy Studies, 10(2), 53-66. Retrieved June 11, 2017 from http://jceps.com/index.php? page $\mathrm{ID}=$ article\&articleID $=$

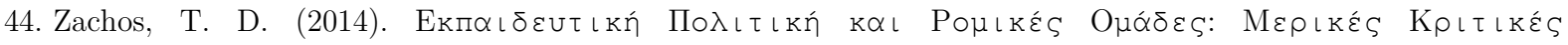

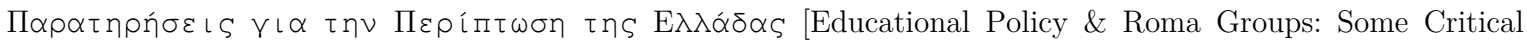

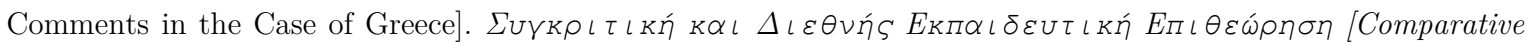
and International Education Review], 22, 129-143. 
45. Zachos D. and Michailidou, A. (2014). "Others" in Textbooks: The Case of Greek Sixth Grade's History Textbook. Theory in Action, 7(3), 1-25.

46. Zachos, D. (2017a). Teachers' Perceptions, Attitudes and Feelings Towards Pupils of Roma Origin. International Journal of Inclusive Education, 21(6). DOI: 10.1080/13603116.2017.1326176

47. Zachos D. (2017b). Roma, Curriculum and Textbooks: The Case of Greece. Cognitive Education, 8(9).

48. Zachos D. (2018, April 30). How Europe Gets Roma Culture and Identity Wrong. Social Europe. Retrieved June 11, 2018 from https://www.socialeurope.eu/roma-culture-and-identity

49. Zake, D. (2011). Qualitative Education for Roma Students: A Pedagogical Model for Sustainable Development. Journal of Teacher Education for Sustainability, 12(2), pp. 27-37. 